\title{
Liquid hydrocarbons from coal beds - risk factor for the underground work environment - Case study
}

\author{
Cristian Tomescu, ${ }^{1,}$, Constantin Lupu ${ }^{1}$, Maria Prodan $^{1}$, Ion Gherghe ${ }^{1}$, and Florin Radoi ${ }^{1}$ \\ ${ }^{1}$ National Institute for Research and Development in Mine Safety and Protection to Explosion - \\ INSEMEX, 32-34 G-ral Vasile Milea Street, 332047, Petroşani, Hunedoara County, Romania
}

\begin{abstract}
Liquid hydrocarbons from the coal bed and surrounding rocks, besides the stored gases, methane, carbon dioxide, carbon oxide, generate the increase of the risk factor from the occupational health and safety point of view. If for reducing the gas concentrations level and the methane emissions in order to increase the safety in exploitation exist well-known solutions and methods, the oxidation or self-oxidation of the hydrocarbons from the coal bed generate a series of compounds, reaction products over maximum admitted concentrations which give birth to a toxic atmosphere and which is hazardous for workers, at the same time inducing an error in noting the occurrence of a spontaneous combustion phenomena, a major risk for the workers and for the mineral resource. This paper represents a case study performed in one underground mine unit from Jiu Valley and presents the analysis for underground environment factors monitoring and for solutions for diminishing the OHS risk factors.
\end{abstract}

\section{Introduction}

Located in the west area of the Jiu Valley coal, the Uricani mine is a unit that operates coal mining for about 70 years. Being in a closure plan, the mine unit conducts the extraction process unit in parallel with the closure plan according to the Project schedule.

The production capacity $-8,000$ tonnes / month of operation is given by the exploitation of the $3^{\text {rd }}$ layer form the horizon 300 in an undermined front bench stope. The good progress of the extraction process is disrupted by the risk factors of the working underground environment: the development of spontaneous combustion phenomenon with toxic gases emissions and in the most undesirable case, the forming of methane-air mixtures that can generate an explosion for the methane concentrations between 5-15\% vol. An additional danger coefficient is given by the presence in the coal layer of the liquid hydrocarbons specifics to the mining field of Uricani Mine and whose oxidation products lead to the mislead interpretation of some phenomena and implicitly in applying the proper preventing measures.

* Corresponding author: cristian.tomescu@,insemex.ro 
The case study is focused in two vectors: the analysis of direct and indirect measurements and gas concentrations, determinations and interpretations, which may highlight an evolution/ involution of a phenomenon of spontaneous combustion and the analysis of a mixture of explosive gases that decrease the lower explosion limit of methane.

The measurement locations were located in different points of the related mining works of the undermined bench stope panel $7,3^{\text {rd }}$ layer, block IV, horizon 300, in the base gallery, the base profile, the stair profile and in the coal bench drillings.

\section{Liquid hydrocarbons and their oxidations}

In the Uricani minefield, the liquid hydrocarbons are frequently scattered in the coal layer 5 and sporadic in layer 3. The structure of liquid hydrocarbons from carbonaceous mass same as the oily ones, is expected not to suffer chemically changes under certain conditions. However, occurs an uncontrollable slow oxidation, also called autoxidation, which can occur even in a stable storage medium [1].

The conditions needed for the autoxidation to takes place in a system are: suitable pressure of oxygen 0.07 bar, the temperature between $30-120^{\circ} \mathrm{C}$, the presence of a certain quantity of hydroxides to initiate the process or other factors that favours the formation of free radicals such as for example, the active metal ions, water, microorganisms [2]. Since the reactions that occur during the phenomenon of autoxidation results carbonyl compounds as the case of carbon monoxide, forming the final stable compounds such as alcohols, ketones, acids which can react further for the formation of macromolecular substances responsible for the high viscosity of hydrocarbon subjected to oxidation $[3,5]$.

From the Uricani Mine samples it was observed the liquid hydrocarbons have a high viscosity, similarly with the hydrocarbons subjected to oxidation process. The presence of this kind of hydrocarbons, their high viscosity and the presence of the factors that favours the initiation of the oxidation process such as metallic ions from coal suggest the fact that the liquid hydrocarbon that are in the mining works can be subjected to this phenomenon that can cause as reaction product carbon monoxide.

\section{The exploiting of the panel 7, gas emanations and measurements}

The front stope panel 7, $3^{\text {rd }}$ layer, block S IV, hor. 300 was put into operation using the operating undermined bench under natural ceiling, which involves the exploitation of thick layers of coal and reduced inclination (the inclination of the layer $\alpha$ layer $\leq 22^{0}$ ), method of operation which falls in those who provide descending extraction of the deposit sliced / undergrowth, with long directional slope, with the directing the mining pressure by total collapse of coal and the surrounding rocks behind the front. This panel sub traverse the individual stope front panel $1,3^{\text {rd }}$ layer, block S IV, hor. 300 , which has been exploited in the previous years.

The coal exploited in the undermined bench panel front $7,3^{\text {rd }}$ layer, block S IV, hor. 300 is characterized as a low self-igniting risk coal and is classified in Group II in terms of risk (tendency) to self-ignition. The needed air flow for stope ventilation is $\mathrm{Qr}=335 \mathrm{~m} 3 / \mathrm{min}$.

The production capacity was monitored by direct measurement with portable gasanalysers $\left(\mathrm{O}_{2}, \mathrm{CO}_{2}, \mathrm{CH}_{4}\right.$ and $\left.\mathrm{CO}\right)$, and indirectly through gas chromatographic analysis of samples of air taken from the underground atmosphere to determine the fire indices (index Graham- $\mathrm{R}_{1}$, breathing $\mathrm{R}_{2}$ index, ethylene and acetylene $\mathrm{C}_{2} \mathrm{H}_{4}, \mathrm{C}_{2} \mathrm{H}_{2}$ ) through which is evaluated the security status of the coal face in terms of the occurrence of a spontaneous 
combustion (self-heating to self-ignition) and determinations the working environment temperature.

During the monitoring period were identified variable concentrations of carbon monoxide, measured directly with portable gas analysers, highlighted in mining nest from the exploited space and from research drillings with an increasing trend over 100 times the maximum permitted concentration $\mathrm{CO} \geq 2000 \mathrm{ppm}$ (maximum permissible concentration of $\mathrm{SSM}$ Regulation, $\mathrm{CO}=20 \mathrm{ppm}$ ), concentrations $\mathrm{CO}_{2} \geq 5 \%$ vol., methane $\mathrm{CH}_{4}=5.0 \%$ vol., with the detection of specific odours of hydrocarbons. The evolution of the temperature of the coal face including the undermined dislodged coal bench did not exceed $22^{\circ} \mathrm{C}$ [6].

The measurements and analysis on gas chromatograph air samples taken from the monitored area revealed that the concentrations of carbon monoxide was not the same as that measured directly, but 3-5 times lower, and ethylene exceeded 50 times (over $500 \mathrm{ppm}$ ) concentration of self-heating phase $(10 \mathrm{ppm})$ with to $0,8 \mathrm{ppm}$ acetylene (trace). They were found high concentrations of heavy hydrocarbons (methane, ethane, propane, propene, isobutane, n-butane) and high concentrations of hydrogen until $\mathrm{H}_{2}=0.43 \%$ vol.

\section{The interpretations of results}

\subsection{The risk of evolution and the development of spontaneous combustion}

It is known from literature and from the good engineering practice undertaken at INCDINSEMEX Petrosani, that the key indicator element for assessing the emergence and development of a spontaneous combustion phenomenon consists of the concentration of carbon monoxide, correlated with certain temperature thresholds from the self-heated coal. At high detected concentrations the interpretation of the phenomenon would have a diagnosis for auto-ignition of the coal mass, with the measured values and compared to the model of evolution and involution of the phenomenon of spontaneous combustion based on the correlation between the variation of carbon monoxide in time $(\tau)$ and developed temperature ( $\mathrm{t}$ ) during the process - Bystron diagram (Figure 1).

The research, observations and findings proved otherwise, because, the absence of the factors specific to the self-heating self-igniting phenomenon: smoke, fog, dew, heated coal mass (coke), a burning smell and a rise in temperatures air from the underground. The big difference between the concentrations of carbon monoxide measured with portable equipment and the ones determined by Gas Chromatography, represents the result of interference from the presence of high concentrations of heavy liquid hydrocarbons, including those aromatics.

The big difference between the concentrations of carbon monoxide determined by the two methods are reflected in the variation of the fire indices, thus, taking into account the most critical periods, with the highest values recorded (September and October from monitoring times, May-December 2016).

To have a clear view and an element of comparison, from the literature is given by the value interpretation of the fire indices used in Romania (Graham - $R_{1}$, respiration index $R_{2}$, ethylene and acetylene $\mathrm{C}_{2} \mathrm{H}_{4}, \mathrm{C}_{2} \mathrm{H}_{2}$ ): 


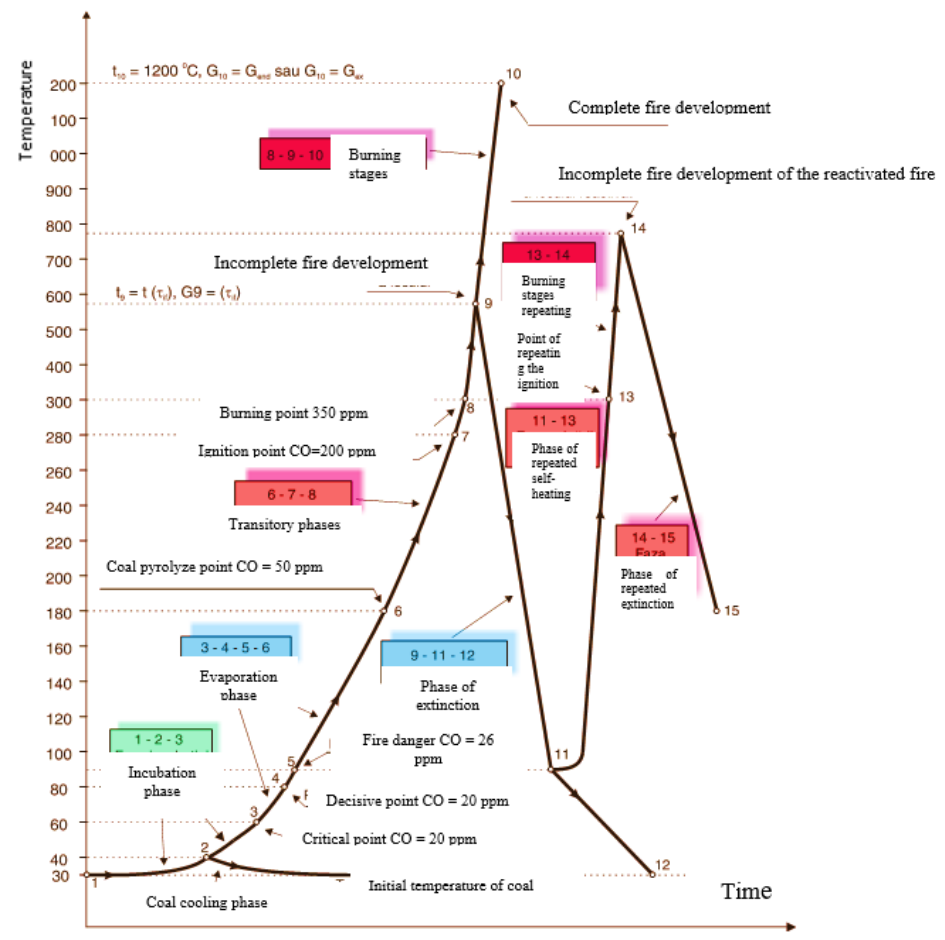

Fig.1. Bystron Diagram

Graham Index $\left(\mathrm{R}_{1}\right)$,

$$
R_{1}=\frac{+\Delta \mathrm{CO}}{-\Delta \mathrm{O}_{2}} \times 100
$$

where:

$+\Delta \mathrm{CO}-$ represent the $\mathrm{CO}$ concentration growth towards the reference level

- $\Delta \mathrm{O}_{2}$ - represents the $\mathrm{O} 2$ concentration decrease towards the initial concentration of $\mathrm{O}_{2}$ from the fresh gas

Interpretation:

- $\mathrm{R}_{1}<0,4$ - normal situation

- $R_{1} \geq 0,4$ - start of self-ignition

- $\mathrm{R}_{1}=2-3$ - lower limit of self-ignition

- $\mathrm{R}_{1}=25$ - endogenous fire

The breathing index $\left(\mathrm{R}_{2}\right)$

$$
R_{2}=\frac{+\Delta \mathrm{CO}_{2}}{-\Delta \mathrm{O}_{2}} \times 100
$$

where:

$+\Delta \mathrm{CO} 2$-represent the $\mathrm{CO}_{2}$ concentration growth towards the reference level,

$-\Delta \mathrm{O} 2-$ represent the $\mathrm{O}_{2}$ concentration decrease towards the initial concentration of $\mathrm{O}_{2}$ from the fresh gas. $(20,9 \%$ vol.)

Interpretation:

- $\mathrm{R}_{2} \leq 60$ normal situation 
- $\mathrm{R}_{2}>60$ shows the existence of a spontaneous combustion phenomena, where $\mathrm{CO}, \mathrm{CO}_{2}$ and $\mathrm{O}_{2}$ gas concentrations are in $\%$ volume, measured at the outlet downstream of the oxidation furnace

$>\quad$ Ethylene index $\% \mathrm{C}_{2} \mathrm{H}_{4}$

- $\mathrm{C}_{2} \mathrm{H}_{4} \geq 0,001 \%$ vol. Existence of a self-ignition process

- $\mathrm{C}_{2} \mathrm{H}_{4} \geq 0,06 \%$ vol. endogenous fire

$>\quad$ Acetylene index $\% \mathrm{C}_{2} \mathrm{H}_{2}$

- $\mathrm{C}_{2} \mathrm{H}_{2}$ traces - self heating process

- $\mathrm{C}_{2} \mathrm{H}_{2} \geq 0,0001 \%$ self-ignition process

For the characterisation of the phenomenon are taken into account these indices, and for the interpretation of the phenomenon are considered the values that indicates the most dangerous situation [6].

Thus, it was determined the values of the indices from the critical period:

- The Graham Index R1, calculated in the case of portable equipment for CO, varies between $\mathrm{R} 1=0,22-5,10$;

- The Graham Index R1, calculated in the case of gas-chromatographic determination of CO varies between $\mathrm{R} 1=0,08-1,31$;

- The breathing index R2, calculated in the case of portable equipment for $\mathrm{CO} 2$, varies between R2=20,8-147,3;

- The breathing index R2, calculated in the case of gas-chromatographic determination of $\mathrm{CO} 2$ varies between $\mathrm{R} 2=43,1-66,8$;

- Ethylene, C2H4 = 0,0001-0,0542\%;

- Acetylene, $\mathrm{C} 2 \mathrm{H} 2=0,8 \mathrm{ppm}$ (traces);

- The hydrogen concentration determined in the laboratory, $\mathrm{H} 2=0,0014-0,315 \%$

After analysing the results of measurements and determinations, it appears as logical consequence of interpretation that across exploited space of the undermined bench stope, panel $7,3^{\text {rd }}$ layer, block IV, horizon 300 , found an atypical phenomenon similar to the selfheating phenomenon at auto-ignition limit, specific to the oxidation of coal, but generated by the oxidation of liquid hydrocarbon, thus a pseudo-phenomenon of spontaneous combustion

\subsection{The estimation of the gas mixtures explosivity}

Estimation of the degree of explosiveness of the mixture of gases in the samples analyzed was conducted solely on the basis of the concentrations determined in the samples. Flammable gas analysed were the following: hydrogen, carbon monoxide, methane, ethane, ethylene, propane, propene, acetylene, iso-butane and n-butane.

The lower explosive limit of a combustible gas mixture can be estimated using the derivation of the Le Chatelier's. The derivation uses only the flammable components of the mixture with the molar fractions corresponding to the adjusted relative percentage as follows:

$$
\% L_{I E} \text { mix }=\frac{1}{\sum \frac{\mathrm{x}_{\text {inflam }}}{\% \mathrm{LIE}_{\mathrm{i}}}} x 100
$$

where:

- \% LIE $\mathrm{LIx}_{\mathrm{mix}}=$ lower explosion limit (LIE) of the mixture;

- $\mathrm{Xi}_{\text {inflam }}=$ the molar fraction correspondent to the fuel gas;

- $\mathrm{LIE}=$ lower explosion limit (LIE) of the individual component. 
Explosivity of a gas mixture can be determined by estimating the lower explosion limit of the mixture applying Le Chatelier's principle and then comparing the result with the overall percentage of flammable substances in the mixture. If the total percentage of flammable substances in the mixture is higher than the lower calculated limit of the mixture, the mixture is considered explosive.

Explosivity estimation of a gas mixture using the enounced principle only take into account the fuel components determined in the mixture. Because an explosive mixture maintains and propagate the flame, the oxygen concentration must be greater than the limiting oxygen concentration [1].

In the samples analysed, the major component is methane and oxygen concentration value limit varies between $10.7 \%$ and $12 \%$ depending on the explosion vessel used for determining explosion [4].

For sample no. 1, taken from exploited space the date are given in Table 1.

Table 1. Sample no. 1 results analysis

\begin{tabular}{|c|c|c|}
\hline Fuel gas component & Concentration [\%vol.] & LIE [\%] \\
\hline Hydrogen & 0,430 & 4 \\
\hline Methane & 9,260 & 5 \\
\hline Ethane & 0,029 & 3 \\
\hline Ethylene & 0,015 & 2,70 \\
\hline Propane & 0,170 & 2,1 \\
\hline Propene & 0,004 & 2 \\
\hline Iso-Butane & 0,022 & 1,8 \\
\hline N-Butane & 0,017 & 1,6 \\
\hline Carbon Monoxide & 0,050 & 12 \\
\hline
\end{tabular}

$\mathbf{L I E}_{\mathbf{m i x} 1}=4,79 \%$

The total percentage of flammable substances in the mixture $=9.99 \%$. According to the principle stated above, because the percentage of flammable substances in the mixture is greater than the LIE calculated, analyzed gas mixture is considered explosive.

No. 2 sample, taken from exploited space the date are given in Table 2.

Table 2. Sample no. 2 results analysis

\begin{tabular}{|l|c|c|}
\hline \multicolumn{1}{|c|}{ Fuel gas component } & Concentration [\%vol.] & LIE [\%] \\
\hline Hydrogen & 0,27 & 4 \\
\hline Methane & 5,17 & 5 \\
\hline Ethane & 0,009 & 3 \\
\hline Ethylene & 0,008 & 2,70 \\
\hline Propane & 0,089 & 2,1 \\
\hline Propene & 0,002 & 2 \\
\hline Iso-Butane & 0,146 & 1,8 \\
\hline N-Butane & 0,012 & 1,6 \\
\hline Carbon Monoxide & 0,019 & 12 \\
\hline
\end{tabular}

$\mathbf{L I E}_{\mathbf{m i x} 2}=4,61 \%$ 
The total percentage of flammable substances in the mixture $=5,72 \%$

Because the percentage of flammable substances in the mixture is greater than the lower explosion limit calculated, analysed gas mixture is considered explosive.

No.3 sample, taken from the gallery profile headaches have input in Table 3.

Table 3. Sample no. 3 results analysis

\begin{tabular}{|l|c|c|}
\hline \multicolumn{1}{|c|}{ Fuel gas component } & Concentration [\%vol.] & LIE [\%] \\
\hline Hydrogen & 0,009 & 4 \\
\hline Methane & 0,740 & 5 \\
\hline Etane & 0,003 & 3 \\
\hline Etylene & 0,0008 & 2,70 \\
\hline Propane & 0,0155 & 2,1 \\
\hline Propene & 0,0001 & 2 \\
\hline Iso-Butane & 0,0033 & 1,8 \\
\hline N-Butane & 0,0004 & 1,6 \\
\hline Carbon Monoxide & 0,0079 & 12 \\
\hline
\end{tabular}

$\mathbf{L I E}_{\operatorname{mix} 3}=4,82 \%$

The total percentage of flammable substances in the mixture $=0.78 \%$. The percentage of flammable substances in the mixture is lower than the lower explosion limit calculated that, analysed the gas mixture is not considered explosive.

\section{Action measures for the risk minimisations}

To reduce the risk factors were taken a series of preventive measures to prevent / combat the emerging phenomenon of spontaneous combustion:

- Setting up a pillar protection and enforcement of a new alignment of the stope panel 7;

- Monitoring the atmosphere of the front stope front in terms of gas concentrations (per shift);

- Monitoring of air flow rates in sub-circuit bench stope front panel undermined 7, 3rd, block

S IV, hor. 300 (weekly);

- The intensively treatment of the exploited space with aerosols (trisodium phosphate $24001 /$ day) and sodium bicarbonate in an $(8-10 \mathrm{~kg} / \mathrm{m} 2)$;

- Instrumentation of fly ash from exploited space through the liner or by means of boreholes siltation (intensively);

- Monitoring of upper areas of construction insulation layer (5) respectively in adjacent areas (layer 3).

\section{Conclusions}

The research paper is represented by a case study at Uricani mine from the Jiu Valley coal basin, the deposit that has liquid hydrocarbons and directed on two analyses: monitoring gas concentration, determinations and interpretations that may highlight a trend of evolution / involution of a combustion phenomenon and forecasting the explosion degree of the gas mixtures.

- Assessment of the risk and developing a spontaneous combustion phenomenon was performed using fire indices Graham- $\mathrm{R}_{1}$, breathing $\mathrm{R}_{2}$, Ethylene $-\mathrm{C}_{2} \mathrm{H}_{4}$, acetylene $-\mathrm{C}_{2} \mathrm{H}_{2}$ determined from direct measurements of gas concentrations $\mathrm{O}_{2}, \mathrm{CO}_{2}$ and $\mathrm{CO}$ and indirectly 
by analysis by gas - chromatograph of air samples taken from the underground atmosphere and temperature measurements;

- Direct measurements in places established revealed an overrun of about 100 times the maximum permitted concentration $\mathrm{CO} \geq 2000 \mathrm{ppm}$, compared to the maximum allowed by Regulation SSM, concentrations $\mathrm{CO}_{2} \geq 5 \%$ vol., Methane $\mathrm{CH}_{4}=5.0 \%$ vol., with the detection of specific odours of liquid hydrocarbons. The evolution of the temperature of the coal face including the undermined coal bank dislodged from the temperature did not exceed $22^{\circ} \mathrm{C}$;

- Gas chromatograph analyses revealed heavier hydrocarbons presence (methane, ethane, propane, propylene, iso-butane, n-butane) and a difference in the concentration of carbon monoxide than those measured directly by portable analysers, as a result interference measurements with their influence on components of appliances and sensors default difference value indices of fire;

- After analysing the results of measurements and determinations, it was found that in the bench stope front panel undermined $7,3^{\text {rd }}$, block S IV, hor. 300 appeared an atypical phenomenon similar to the self-heating to autoignition limit specific to coal oxidation, but generated by the oxidation of liquid hydrocarbons, ie a phenomenon of pseudo-spontaneous combustion, because of the absence of the other specific elements of a self-heating to selfigniting phenomenon: smoke, fog, dew, heated coal mass, burning smell and a rise in temperature of the working environment;

- Estimating the degree of explosiveness of the mixture-gas samples analysed was made solely on the basis of concentrations determined in the samples. Inflammable gas samples were pursued: hydrogen, carbon monoxide, methane, ethane, ethylene, propane, propene, acetylene, Iso-butane and n-butane. The samples were analysed to estimate the lower explosion limit, respectively explosivity, samples that were found the highest or lowest gas concentrations and average sample. In the samples analysed, the major component is methane and oxygen concentration value limit varies between $10.7 \%$ and $12 \%$;

- To minimize the risks and to increase the safety of mineral resources, health and safety of workers in underground, were taken a series of technical and organizational measures, prophylactic prevention / combating the emerging phenomenon of spontaneous combustion, which gave great results by eliminating syncope in extraction process.

\section{References}

1. A., Isaac, G., Zlochower, M. Green, Journal of Loss Prevention in the Process Industries, 22 (4), 499-505 (2009)

2. D., Crowl, American Institute of Chemical Engineers, (New York, 2003)

3. D., Cioclea, I., Toth, Prevenirea combustiilor spontane la extragerea carbunilor prin metoda de exploatare cu banc subminat, (Editura Agora, 2004)

4. C., Tomescu, Masuratorile efectuate in teren la Mina Uricani, Rapoarte tehnice lunare, (INCDINSEMEX Petrosani, 2016)

5. I., Dunn, Biotechnology and Bioengineering, 10 (6), 891-894 (1968)

6. X., Ma, A., Shou, A., Song, Catalysis Today, 123 (1-4), 276-284 (2007) 